\title{
ANALISA TINGKAT KEPUASAN PASIEN RAWAT JALAN DI INSTALASI FARMASI BUDI SETIA LANGOWAN KABUPATEN MINAHASA
}

\author{
Gerald N.P. Tulung ${ }^{1)}$, Gayatri Citraningtyas ${ }^{1)}$, Imam Jayanto ${ }^{1)}$ \\ 1) Program Studi Farmasi FMIPA UNSRAT Manado, 95115
}

\begin{abstract}
The quality of health services is classified as good if the health services provided could cause satisfaction to each patient in accordance with the level of satisfaction of the average population who are the main target of the health service. The purpose of this study was to determine the level of satisfaction of outpatients with the quality of pharmacy services at the Pharmacy Installation at Budi Setia Langowan Hospital. This research is a crosssectional study with the study sample determined using the accidental sampling method, which is a sampling technique by taking samples randomly. Data were taken by prospective way then analyzed using statistical methods with SPSS analysis program, using bivariate analysis to test the relationship between independent variables, namely the level of outpatient satisfaction with the dependent variable namely Outpatient Service Quality (Tangibles, Reliability, Responsiveness, Assurance, and Empathy) given by the hospital to outpatients. The results showed that the value of outpatient patient satisfaction was at a positive index with a value of 0.07 with a CSI value of 87.74, which was in the very satisfied range, thus stating overall of the patients receiving pharmaceutical services at the Budi Setia Langowan Pharmacy Installation, had felt very satisfied.
\end{abstract}

Keywords: Analysis of the level of satisfaction of outpatients, Budi Setia Langowan.

\begin{abstract}
ABSTRAK
Kualitas pelayanan kesehatan digolongkan baik jika pelayanan kesehatan yang diberikan dapat menimbulkan rasa puas pada setiap pasien yang sesuai dengan tingkat kepuasan ratarata penduduk yang menjadi target utama dari pelayanan kesehatan tersebut. Tujuan penelitian ini untuk mengetahui tingkat kepuasan pasien rawat jalan terhadap kualitas pelayanan kefarmasian di Instalasi Farmasi Rumah Sakit Budi Setia Langowan. Penelitian ini merupakan penelitian cross-sectional dengan sampel penelitian ditetapkan menggunakan metode accidental sampling, yaitu teknik pengambilan sampel dengan mengambil sampel secara bebas. Data yang diambil secara prospektif kemudian dianalisis menggunakan metode statistik dengan program analisis SPSS, dengan menggunakan Analisis bivariat untuk melakukan uji hubungan antara variabel bebas yaitu tingkat kepuasan pasien rawat jalan dengan variabel terikat yaitu Mutu Pelayanan Rawat Jalan (Tangibles, Reliability, Responsiveness, Assurance, dan Emphaty) yang diberikan Rumah Sakit kepada pasien tawat jalan. Hasil penelitian menunjukan nilai Ikj kepuasan pasien rawat jalan berada pada indeks positif dengan nilai 0,07 dengan nilai CSI sebesar 87,74 yang berada pada rentang sangat puas, sehingga menyatakan secara keseluruhan pasien yang menerima pelayanan kefarmasian di Instalasi Farmasi Budi Setia Langowan sudah merasa sanggat puas.
\end{abstract}

Kata kunci : Analisa tingkat kepuasan pasien rawat jalan, Budi Setia Langowan. 


\section{PENDAHULUAN}

Masalah yang banyak dihadapi secara umum oleh rumah sakit adalah rumah sakit belum bisa memberikan sesuatu hal yang benar-benar diinginkan pasien. Faktor tersebut dikarenakan pelayanan yang diberikan masih berkualitas rendah sehingga belum dapat menmberikan pelayanan yang diharapkan pasien. Penurunan tingkat kunjungan rumah sakit salah satunya dapat terjadi apabila pelayanan yang diberikan Instalasi Farmasi Rumah Sakit buruk. Masalah yang terjadi jika pasien tidak mendapatkan kepuasan dari kualitas pelayanan yang diterima maka pasien cenderung mengambil keputusan untuk tidak melakukan kunjungan kembali pada rumah sakit tersebut (Megawati, 2015).

Kualitas pelayanan kesehatan digolongkan baik jika pelayanan kesehatan yang diberikan dapat menimbulkan rasa puas pada individu dari setiap pasien yang sesuai dengan tingkat kepuasan rata-rata penduduk yang menjadi target utama dari pelayanan kesehatan tersebut. Tingkat kualitas pelayanan yang diterima dari tiap pasien harus sama tanpa ada perbedaan yang membuat pasien merasakan ketidanyamanan dalam pelayanan yang diterima (Aryani, 2015).

\section{METODOLOGI PENELITIAN}

\section{Waktu dan Tempat Penelitian}

Penelitian ini dilaksanakan pada bulan Agustus 2019 di Instalasi Farmasi di Rumah Sakit Budi Setia Langowan.

\section{Jenis Penelitian}

Penelitian ini merupakan penelitian cross-sectional, dengan menyebarkan kuesioner kepada responden rawat jalan di Instalasi Farmasi di Rumah Sakit Budi Setia Langowan.

\section{Populasi dan Sampel Penelitian}

Populasi dalam penelitian ini adalah seluruh pasien rawat jalan (pasien umum dan pasien peserta asuransi) yang berkunjung ke instalasi farmasi Rumah Sakit Budi Setia Langowan. Sampel dalam penelitian ini menggunakan metode accidental sampling. Jumlah sampel yang digunakan dalam penelitian ini sebanyak 185 sampel.

Penentuan jumlah sampel menggunakan rumus Slovin sebagai berikut :

$n=\frac{\mathrm{N}}{1+\mathrm{N}\left(e^{2}\right)}$

Keterangan:

$n$ : Besar sampel

$\mathrm{N}$ : Populasi yang diketahui

$\mathrm{e}:$ Margin of error. $=(0,05)$.

Kriteria Inklusi:

1. Bersedia menjadi responden

2. Pasien atau keluarga pasien yang bisa baca dan tulis.

3. Pasien rawat jalan yang sudah 2 kali menerima pelayanan kefarmasian di Instalasi Farmasi Rumah Sakit Budi Setia Langowan

Kriteria Eksklusi:

1. Pasien yang sudah pernah menjadi responden dalam penelitian ini. 


\section{Pengumpulan Data}

Teknik pengumpulan data adalah data primer dan data sekunder. Data primer diperoleh melalui kuesioner yang disebarkan kepada responden yang menjadi subjek penelitian. Data sekunder diperoleh dari data kunjungan pasien rawat jalan di Instalasi Farmasi Rumah Sakit Budi Setia Langowan dibulan Agustus.

\section{Uji Validasi}

Uji validitas digunakan untuk mengetahui butir pernyataan dalam kuesioner yang dapat digunakan dalam penelitian. Uji validitas kuesioner harapan dan kenyataan disebarkan pada 30 responden pertama pada awal penelitian. Kusioner harapan dan kenyataan berisikan 21 item pernyataan yang terbagi dalam 5 kelompok dimensi yaitu berwujud (tangibles), empati (empathy), keandalan (reability), ketanggapan (responsiveness) dan jaminan (assurance). Data yang diperoleh selanjutnya dianalisis dengan menggunakan program analisis statistika dan diuji validitas dengan nilai $r$ hitung hasil uji validitas yang dibandingkan dengan $r$ tabel yaitu 0,361. Hasil yang ditunjukan pada Tabel 2, menunjukan item pernyataan dari kuesioner harapan dan kenyataan sebanyak 21 item dinyatakan valid karena memiliki nilai $r$ hitung lebih besar dari pada nilai $r$ tabel $(0,361)$.

\section{Uji Reliability}

Reliabilitas adalah indeks yang menunjukkan sejauh mana suatu alat ukur dapat dipercaya. Uji reliabilitas yang digunakan adalah uji reliabilitas internal. Item pernyataan kuesioner harapan dan kenyataan yang berjumlah 21 item yang telah dinyatakan valid kemudian akan dilakukan uji reabilitas untuk menentukan apabila konsistensi alat ukur yang digunakan dapat dipercayah diandalkan apabila dilakukan pengukuran kembali. Hasil yang diporel bahwa kuesioner harapan memiliki nilai 0,915 yang artinya sangat baik dan kuesioner kenyataan juga sangat baik karena memiliki nilai diatas 0,8 yaitu 0,928 .

\section{Analisis Data}

Data diambil secara prospektif, kemudian dianalisis menggunakan metode statistik, dengan menggunakan Analisis bivariat. Untuk menilai jawaban responden digunakan skala Likert.

1. Jawaban sangat tidak setuju atau sangat tidak puas diberi bobot 1

2. Jawaban tidak setuju atau tidak puas diberi bobot 2

3. Jawaban setuju atau puas diberi bobot 3

4. Jawaban sangat setuju atau sangat puas diberi bobot 4

Analisis yang digunakan untuk menghitung jumlah total kualitas pelayanan menggunakan model Weighted Servqual dengan rumus :

$$
I k j=\sum_{I=0}^{n}(P i j-E i j)
$$


Keterangan:

$I k j=$ Indeks total kualitas pelayanan

Pij = Performance I pada objek $\mathrm{J}$

Eij = Expectance (harapan atribut pada objek j)

$n \quad=$ Jumlah pernyataan

Berdasarkan hasil dari indeks total kualitas pelayanan dapat diartikan bahwa

1. Indeks nol

Situasi yang menyatakan bahwa tingkat harapan pelanggan sama dengan kinerja yang dihasilkan oleh perusahaan.

2. Indeks negatif

Situasi yang menyatakan bahwa tingkat harapan pelanggan lebih besar dari kinerja aktual yang dihasilkan perusahaan.

3. Indeks positif

Situasi yang menyatakan bahwa tingkat harapan pelanggan mengenai pelayanan yang diterima lebih kecil dari kinerja yang diberikan

Pengukuran costumer satisfaction index untuk menentukan nilai kepuasan, dengan mencari rata-rata dari tingkat harapan dan kenyataan dengan melihat total nilai 0-25 yang berarti sangat tidak puas, 26-50 yang berarti tidak puas, 51-75 yang berarti puas dan 76-100 yang berarti sangat puas.

\section{HASIL DAN PEMBAHASAN}

\section{Karakteristik Responden}

Karekteristik pasien merupakan keseluruhan dari pasien peserta jaminan kesehatan BPJS dan pasien umum tanpa jaminan kesehatan.
Tabel 1. Karakteristik Responden

\begin{tabular}{|c|c|c|}
\hline \multirow[t]{2}{*}{ Karakteristik } & \multicolumn{2}{|c|}{ Total } \\
\hline & $\mathbf{N}$ & $\%$ \\
\hline \multicolumn{3}{|l|}{ Jenis Kelamin } \\
\hline Laki-laki & 72 & 39 \\
\hline Perempuan & 113 & 61 \\
\hline \multicolumn{3}{|l|}{ Usia (Depkes,2019) } \\
\hline 17-24 Tahun & 9 & 5 \\
\hline 25-44 Tahun & 51 & 28 \\
\hline 45-64 Tahun & 86 & 46 \\
\hline$>65$ Tahun & 39 & 21 \\
\hline \multicolumn{3}{|l|}{ Pendidikan Terakhir } \\
\hline SD/Sederajat & 11 & 6 \\
\hline SMP/Sederajat & 58 & 31 \\
\hline SMA/Sederajat & 84 & 46 \\
\hline Perguruan Tinggi & 39 & 17 \\
\hline Total Sampel & \multicolumn{2}{|c|}{185} \\
\hline
\end{tabular}

\section{Uji Validasi}

Uji validitas kuesioner harapan dan kenyataan disebarkan pada 30 responden pertama pada awal penelitian. Kusioner harapan dan kenyataan berisikan 21 item pernyataan yang terbagi dalam 5 kelompok dimensi yaitu berwujud (tangibles), empati (empathy), keandalan (reability), ketanggapan (responsiveness) dan jaminan (assurance). Data yang diperoleh selanjutnya dianalisis dengan menggunakan program analisis statistika dan diuji validitas dengan nilai $r$ hitung hasil uji validitas yang dibandingkan dengan $r$ tabel yaitu 0,361 .

\section{Uji Realibilitas}

Item pernyataan kuesioner harapan dan kenyataan yang berjumlah 21 item yang telah dinyatakan valid kemudian akan dilakukan uji reabilitas untuk menentukan apabila konsistensi alat ukur yang digunakan dapat 
dipercayah diandalkan apabila dilakukan pengukuran kembali. Hasil yang diporel bahwa kuesioner harapan memiliki nilai 0,915 yang artinya sangat baik dan kuesioner kenyataan juga sangat baik karena memiliki nilai diatas 0,8 yaitu 0,928 .

Tabel 2. Uji Validasi

\begin{tabular}{crc}
\hline Pernyataan & \multicolumn{2}{c}{$\mathbf{r}(\mathbf{o , 3 6 1})$} \\
\cline { 2 - 3 } & Harapan & Kenyataan \\
\hline 1 & 0,446 & 0,563 \\
\hline 2 & 0,463 & 0,695 \\
\hline 3 & 0,522 & 0,734 \\
\hline 4 & 0,523 & 0,785 \\
\hline 5 & 0,501 & 0,445 \\
\hline 6 & 0,462 & 0,599 \\
\hline 7 & 0,590 & 0,519 \\
\hline 8 & 0,733 & 0,673 \\
\hline 9 & 0,632 & 0,818 \\
\hline 10 & 0,703 & 0,769 \\
\hline 11 & 0,748 & 0,750 \\
\hline 12 & 0,756 & 0,665 \\
\hline 13 & 0,667 & 0,761 \\
\hline 14 & 0,810 & 0,773 \\
\hline 15 & 0,778 & 0,836 \\
\hline 16 & 0,583 & 0,600 \\
\hline 17 & 0,559 & 0,539 \\
\hline 18 & 0,477 & 0,548 \\
\hline 19 & 0,679 & 0,633 \\
\hline 20 & 0,655 & 0,649 \\
\hline 21 & 0,650 & 0,476 \\
\hline Total Sampel & \multicolumn{2}{c}{30} \\
\hline
\end{tabular}

Tabel 3. Uji Realibilitas

\begin{tabular}{lc}
\hline Total Pernyataan & 21 \\
\hline Cronbach's Alpha $(\mathbf{a}>\mathbf{0 , 6})$ & \\
Harapan & 0,915 \\
Kenyataan & 0,928 \\
\hline Total Sampel & 30 \\
\hline
\end{tabular}

\footnotetext{
Keseluruhan Analisis Tingkat

Kepuasan Pasien Rawat Jalan di Instalasi Farmasi Rumah Sakit Budi Setia Langowan.
}

Tingkat kepuasan pasien rawat jalan terhadap kualitas pelayanan kefarmasian yang diterima di Instalasi Farmasi Rumah Sakit Budi Setia Langowan dapat dinilai dengan menghitung indeks total kualitas pelayanan, yaitu dengan melihat selisih antara tingkat kenyataan dengan harapan pasien.

Tingkat kepuasan pasien ditunjukan pada Tabel 4 secara keseluruhan,yang menyatakan pada tingkat nilai Ikj tertinggi ditempati oleh dimensi jaminan (assurance) dan dimensi berwujud (tangibles) yang menempati tingkat Ikj terendah.

Tabel 4. Keseluruhan Analisis Tingkat Kepuasan Pasien Rawat Jalan di Instalasi Farmasi Rumah Sakit Budi Setia Langowan.

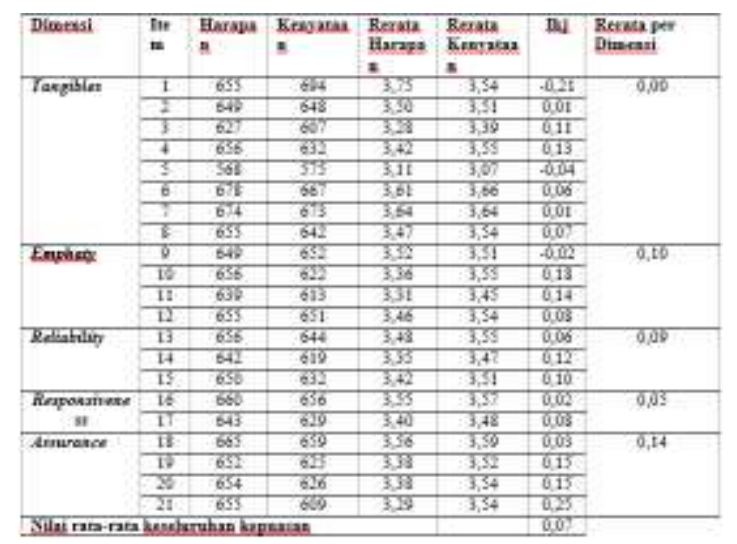

Nilai Ikj dari dimensi jaminan memiliki rata-rata tertinggi yaitu 0,14 yang dianalisis dengan melihat perbandingan antara tingkat kenyataan dan harapan dari pasien. Nilai Ikj dimensi jaminan berada direntang positif yang menyatakan tingkat harapan pasien lebih kecil dari kenyataan pelayanan yang diterima dan memuaskan. 
Total nilai keseluruhan kepuasan pasien dari item pernyataan setiap dimensi memiliki rata-rata nilai 0,07 , yang artinya nilai kepuasan ini beradah pada rentang positif yang berarti tingkat harapan pasien lebih kecil dari kenyataan yang diterima. Keadaan ini menandakan bahwa tingkat kepuasan yang diterima pasien terhadap pelayanan kefarmasian di Instalasi Rumah Sakit Budi Setia Langowan tergolong memuaskan.

\section{Total Penilaian Costumer Satisfaction} Indeks.

Tabel 5 menunjukan nilai $C S I$ sebesar 87,74 yang berarti tingkat kepuasan pasien berada pada rentang
75,0-100 yaitu di tingkat sangat puas. Mean importance score (MIS) menunjukan nilai rata-rata tingkat kepentingan dan mean satisfaction score (MSS) menunjukan nilai rata tingkat kinerja yang dirasakan pasien di Instalasi Farmasi Budi Setia Langowan.

Weight factors (WF) merupakan bobot presentase nilai $M I S$ tiap item pernyataan terhadap total MIS. Weight score (WS) merupakan bobot perkalian antara weight factor dengan rata-rata tingkat kepuasan mean satisfaction. Weight total adalah jumlah dari weight score semua item. CSI didapat dengan membagi weight total dengan skala nominal yang digunakan kemudian dikalikan $100 \%$.

Tabel 5. Total Penilaian Costumer Satisfaction Index

\begin{tabular}{lllllll}
\hline Item & MIS & MSS & WF & WS & WT & CSI \\
\hline 1 & 3,75 & 3,54 & 5,20 & 18,40 & 350,96 & 87,74 \\
2 & 3,50 & 3,50 & 3,85 & 16,98 & & \\
3 & 3,28 & 3,38 & 4,55 & 15,36 & & \\
4 & 3,41 & 3,54 & 4,73 & 16,73 & & \\
5 & 3,10 & 3,07 & 4,30 & 13,19 & & \\
6 & 3,60 & 3,66 & 4,99 & 18,26 & & \\
7 & 3,63 & 3,64 & 5,03 & 18,31 & \\
8 & 3,47 & 3,54 & 4,81 & 17,02 & \\
9 & 3,52 & 3,50 & 4,88 & 17,07 & \\
10 & 3,36 & 3,54 & 4,66 & 16,48 & \\
11 & 3,31 & 3,45 & 4,59 & 15,83 & \\
12 & 3,46 & 3,54 & 4,79 & 16,97 & & \\
13 & 3,4 & 3,54 & 4,82 & 17,07 & & \\
14 & 3,34 & 3,47 & 4,63 & 16,06 & \\
15 & 3,41 & 3,51 & 4,73 & 16,59 & \\
16 & 3,54 & 3,56 & 4,91 & 17,46 & & \\
17 & 3,40 & 3,47 & 4,71 & 16,35 & & \\
18 & 3,56 & 3,59 & 4,93 & 17,71 & & \\
19 & 3,37 & 3,52 & 4,67 & 16,44 & \\
20 & 3,38 & 3,53 & 4,68 & 16,53 & \\
21 & 3,29 & 2,54 & 4,56 & 16,14 & \\
\hline Total & 72,16 & 73,63 & & & & \\
\hline
\end{tabular}




\section{KESIMPULAN}

Pasien rawat jalan yang menerima pelayanan kefarmasian sudah merasa puas akan pelayanan yang diberikan. Hasil penelitian menyatakan bahwa tingkat kepuasan pasien di Instalasi Farmasi Rumah Sakit Budi Setia Langowan CSI sebesar 87.74.

\section{SARAN}

$\begin{array}{ccc}\text { Instalasi } & \text { Farmasi } & \text { harus } \\ \text { mempertahankan } & \text { dan } & \text { lebih }\end{array}$
mengembangkan lagi kinerja pelayanan kefarmasian untuk meningkatkan pelayanan.

\section{DAFTAR PUSTAKA}

Aryani, F. 2015. Analisa Kepuasan Pasien Rawat Jalan Terhadap Kualitas Pelayanan Di Instalasi Farmasi Rumah Sakit Islam Ibnu Sina Pekanbaru. Sekolah Tinggi Farmasi Riau. Pharmacy. 12 (1) 101-111

Departemen Kesehatan Republik Indonesia. 2009. Undang-Undang Republik Indonesia Nomor 44 Tahun 2009 tentang Rumah Sakit. Jakarta.

Megawati. 2015. Penurunan Waktu Tunggu Pelayanan Obat Rawat Jalan Instalasi Farmasi Rumah Sakit BaptisBatu. Jurnal Kedokteran. 28 (2) :163-168

Notoatmodjo, S. 2003. Pendidikan Dan Perilaku Kesehatan. Jakarta: Rineka Cipta. 